stand ist übrigens so unbedeutend, dafs $W$ öhler, welchen die Sache eigentlich angeht, schwerlich die Feder dazu ansetzen wird, den Irrthum aufzuklären.

\title{
Zur Geschichte der Gährung;
}

von C. Schmidt.

Pasteur hat der ausfübrlichen Darstellung seiner Untersuchungen über die Alkoholgährung*) eine historische Einleitung vorausgeschickt, die in Ermangelung genauerer Kenntnifs der deutschen Arbeiten einige Lücken läfst.

Ohne das Verdienst dieser ausgezeichneten Experimentalstudien im Mindesten schwächen zu wollen, finde ich mich zu folgenden Ergänzungen veranlafst.

Das Auftreten von Bernsteinsäure bei Gährung reinen Rohrzuckers, Traubenzuckers und des Traubenmostes ist von mir bereits 1847 durch Analyse des Kalk - und Silbersalzes so wie der reinen Säure festgestellt worden. Ich erhielt aus 2 Kilogrm. Rohrzucker durch Neutralisiren des abgegohrenen Fluidums mit Kalkwasser, Filtriren und Eindampfen circa 8 Grm. bernsteinsauren Kalk, die zur Darstellung des Silbersalzes dienten, so wie durch Destillation von 5 Liter Haut Sauternes, nach vorheriger Neutralisationmit etwas Kalkmilch, im Vacuo bei möglichst niedriger 'Temperatur gegen 4 Grm. reines Kalksuccinat, das theils als solches analysirt wurde, theils zur Darstellung reiner Säure diente. Ich theilte diese

*) Mémoire sur la fermentation alcoolique. Anmales de Chimie et Physigne [3] INVIIT (1860), 323 lis 426. 
interessante Thatsache brieflich Liebig mit, der sie dem Artikel "Gährung" *) mit folgenden Worten einverleibte :

n.... Es ist möglich, dafs die Bildung des Mannits mit der Entstehung der Bernsteinsëure in Verbindung steht, die nach einer briefichen Mittheilung von Dr. Schmidt in Dorpat in allen gegohrenen Flïssigkeiten von ihm aufgefunden und erkannt worden ist..."

Da Piria und Dessaignes fast gleichzeitig die nahen Beziehungen des Asparagins zur Aepfelsäure und Bernsteinsåure, und die weite Verbreitung des Malamids auf den ersten Stufen der Vegetation nachwiesen, so legte ich kein besonderes Gewicht darauf, sondern schrieb die Bildung der Bernsteinsäure der Spaltung in den jungen Hefezellen gebildeten Asparagins zu, das sich später zum Albuminoïdferment des Zellinhalts umsetzt.

Ein weiteres Resultat dieser Vorstudien zu meinen späteren physiologisch - chemischen Arbeiten ist die Widerlegung der seit Thenard traditionell gewordenen Angabe der Gewichtsverminderung der Hefezellen durch die Gährung. Ich bewies experimentell das Gegentheil, eine Gewichtszunahme; bei Gährung mit Zucker allein um circa 50 pC., mit Zucker und Harnstoff gleichzeitig um $60 \mathrm{pC}$. des Anfangsgewichts wasserfreier Hefe $\left.{ }^{* *}\right)$. Ein beispielsweise l. c. aufgeführter Versuch ergab :
A) $5 \mathrm{CC}$. Hefe
$1 \mathrm{Grm}$. Harnstoff
1,3 Grm, Rohrzucker
100 CC. Wasser.
$=0,410$ bei $100^{\circ}$ trocken
B) 5 CC. Hefe
$=0,410$ bei $100^{\circ}$ trocken 3 Grm. Rohrzucker $100 \mathrm{CC}$. Wasser.

Nach vollendeter Gährung wurde der Hefezellen-Bodensatz und der in der Flüssigkeit suspendirte Antheil desselben auf gewogenen Filtern gesammelt; sie wogen bei $100^{\circ}$ getrocknet :

$$
\mathbf{A}=0,655 \mathrm{Grm} . \quad \mathrm{B}=0,628 \mathrm{Grm} .
$$

*) Handwörterbuch der Chemi III, 224.

**) Diese Annalen LXI, 171 (1847). 
Ich lasse den damals gezogenen Schlufs (I. c. S. 171) wörtlich folgen :

„.... An diesen Resultaten ist :

„6) die Vermehrung des Hefenrïckstandes bei den mit Zucker in Berührung gewesenen Hefen auffallend, sei es nun mit oder ohne Harnstoff, der überhaupt den Verlauf der Gährung nicht im Mindesten beeinträchtigt. Der Stickstoffgehalt beider, der mit und ohneZucker gestandenen, erschien ziemlich gleich (10 pC.), der der frischen etwas höher (11,1 pC.), es mul's also offenbar eine Vermehrung der Hefencellulose und zwar höchst wahrscheinlich auf Kosten des Zuckers Statt gefunden haben, was das treffliche Fortvegetiren der auswachsenden Zellen in frischem Zuckerwasser, ohne Gährung zu veranlassen, auch sehr gut erklärt."

Wenn daher Pasteur l. c. p. 402, nachdem er beide Thatsachen, die Bernsteinsäurebildung und das Hefezellenwachsthum während der Gährung, als von ihm 1857 und 1858 entdeckt, aufgeführt, in einer Anmerkung sagt :

1) M. Regnault, sans insister autrement, s'exprime ainsi dans son Traité de Chimie IV, p. 185 4. édit. „On a reconnu, que la levure augmente d'environ le quart de son poids." J'ignore à quelle source $M$. Regnault a puisé cette indication, contraire à l'assertion de M. Thénard, mais vraie d'une maniére générale"; so will ich gern glauben, dafs Pasteur die bezeichneten Thatsachen entdeckt hat, ohne zu wissen, dafs sie bereits seit 10 Jahren bekannt waren, hoffe indessen diesen kleinen historischen Irrthum hiermit berichtigt zu haben.

Dorpat, den 20. December 1862.

B e richtig ung.

Seite $\mathrm{s}$, Zeile 3 von oben ist au setwen :

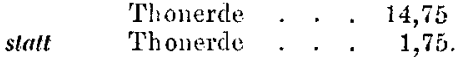

Ausgegeluen am 11. April 1863. 